\title{
Comparative study of hydroalcoholic extracts of Bryophyllum pinnatum and Macrotyloma uniflorum for their antioxidant, antiurolithiatic, and wound healing potential
}

\author{
Chetna Faujdar, Priyadarshini* \\ Department of Biotechnology, JIIT, Noida, India.
}

\begin{tabular}{l}
\hline ARTICLE INFO \\
\hline Article history: \\
Received on: July 6, 2021 \\
Accepted on: September 13, 2021 \\
Available online: January 07, 2022 \\
\hline
\end{tabular}

\section{Key words:}

Urolithiasis, antioxidant, injury, wound healing

\begin{abstract}
The recurrence and associated side effects of modern treatment methods for urolithiasis highlight the need for a safer phytotherapy-based alternative medicine. In the present study, the seeds of Macrotyloma uniflorum (MUE) and leaves of Bryophyllum pinnatum (BPE) were evaluated for their antioxidant, antiurolithiatic, and wound healing potential. Phytochemical screening of extracts was carried out through gas chromatography-mass spectrometry analysis. 2,2-Diphenyl-1-picrylhydrazyl (DPPH) and 2,2'-azinobis (3- ethylbenzothiazoline-6sulfonic acid) diammonium salt (ABTS) assays were used to determine antioxidant potential of plant extracts. Percentage radical activity increased from $1.91 \%$ to $53.99 \%$ in DPPH assay and $39.26 \%-97.44 \%$ in ABTS assay, with an increase in concentration of BPE. Different concentrations of MUE also resulted in dosedependent antioxidant activity from $5.70 \%$ to $45.14 \%$ in DPPH assay and $17.96 \%-96.04 \%$ in ABTS assay. Extracts were investigated for their effect on calcium oxalate monohydrate (COM) crystals-induced Vero cell injury. BPE resulted in the retention of $98.5 \%$ viability after COM crystal exposure to Vero cells against the injured group (57.44\%). Similarly, retained cell viability was found to be in the range of $77.4 \%-90.74 \%$ with different MUE concentrations. Wound healing potential was examined through scratch assay. Along with the prevention of cell injury, extracts also accelerated the wound closure rate as compared to control. Treatment with EC50 and EC90 of BPE resulted in $84.48 \%$ and $74.08 \%$ wound closure, respectively, as compared to the control group (73.79\%). However, EC50 and EC90 of MUE resulted in 85.66\% and $91.09 \%$ wound closure, respectively. The present study concludes the effectiveness of these herbal extracts in minimizing risk factors leading to urolithiasis.
\end{abstract}

\section{INTRODUCTION}

Urolithiasis is a disease caused due to the precipitation and retention of crystal-forming salts within the kidneys. The disease is marked by a recurrence rate of approximately $40 \%$ in 5 years of initial treatment [1]. Currently available medical expulsive therapy is a wait-and-watch kind of approach where success rate depends upon a number of factors such as location of the stone, size of the stone, associated obstructions, etc. [2]. The high recurrence rate of urolithiasis [3] and risk factors associated with synthetic medicines [4] have necessitated the need for safer,

*Corresponding Author

Priyadarshini, Department of Biotechnology, JIIT, Noida, India.

E-mail:priyadarshini@mail.jiit.ac.in reliable, cost-effective, and noninvasive alternatives to manage urolithiasis. During the last few decades, tremendous research has been focused on revealing the role of medicinal plants in the management of urolithiasis. Traditional medicines have been known to result in significant outcomes and play a critical role in treating and preventing human ailments along with paving the way for discovering new drugs. Antiurolithiatic herbs have been used to treat or prevent lithiasis worldwide throughout history.

The interaction of calcium oxalate monohydrate (COM) crystals with renal tubular cells elevate the production of reactive oxygen species (ROS) and stimulate epithelial cell injury, leading to inflammation and eventually cell death $[5,6]$. Renal epithelial cells 
injury by COM crystals provide adhesion sites for crystals, which serve as fixed particles for stone formation [7,8]. Epithelial cell injury also adds oxidative stress, further increasing the chances of stone formation [9]. Considering the role of oxidative stress, treatment modality for urolithiasis should also include therapeutic agents possessing antioxidant abilities. It is a proven fact that the plants having diuretic and antioxidant activities possess inhibitory effects on crystallization, nucleation, and aggregation of crystals, thus having antiurolithiatic activity [10]. Both the plants used in this study have been explored for their diuretic, antispasmodic, antioxidant, and other medicinal properties yet not well explored for their antiurolithiatic property [11-13]. These plants possess strong historical background for being used traditionally as antiurolithiatic agents [14-16]. Therefore, in the present investigation, we have compared the effect of hydroalcoholic extracts of two traditional medicinal plants Bryophyllum pinnatum (BPE) and Macrotyloma uniflorum (MUE) on ROS, COM crystal-induced cell injury, and wound healing to evaluate their antiurolithiatic potential.

\section{MATERIALS AND METHODS}

\subsection{Materials}

\subsubsection{Chemicals}

2,2-Diphenyl-1-picrylhydrazyl (DPPH), 2,2'-azinobis (3ethylbenzothiazoline-6-sulfonic acid) diammonium salt (ABTS), and dimethyl sulfoxide (DMSO) were purchased from SigmaAldrich. Fetal bovine serum (FBS), Dulbecco's modified Eagles's medium (DMEM), and 3-(4,5-dimethylthiazol-2-yl)-2,5-diphenyl$2 \mathrm{H}$ tetrazolium bromide (MTT) were purchased from HiMedia Laboratories, India. Remaining chemicals were purchased from Central Drug House (P) Ltd (CDH) fine chemicals, India.

\subsubsection{Plant materials}

Plants and seeds of BPE and MUE, respectively, were collected locally and identified at the Department of Botany, University of Delhi. Voucher specimens of the authenticated BPE (accession number DUH14500) and MUE (accession number DUH14479) were submitted in the herbarium unit for future reference.

\subsubsection{Cell culture}

Vero cells were procured from the National Centre of Cell Sciences (NCCS, Pune, India). The cells were maintained as subconfluent monolayers in DMEM supplemented with $10 \%$ FBS and $1.2 \%$ antibiotics (penicillin-streptomycin) in a humidified incubator at $37^{\circ} \mathrm{C}$ with $5 \% \mathrm{CO}_{2}$.

\subsection{METHODS}

\subsubsection{Preparation of plant extracts}

The leaves of BPE ( $50 \mathrm{~g})$ were crushed to form a paste and mixed with $70 \%$ ethanol, while the powdered seeds of MUE ( $5 \mathrm{~g})$ were mixed with $70 \%$ methanol to prepare hydroalcoholic extracts. After filtration and solvent evaporation, the obtained concentrate was lyophilized and stored in air-tight containers at $4^{\circ} \mathrm{C}$ for further use. The percentage yield of each extract was calculated using the following formula:

$$
\% \text { Yield }=\left[\begin{array}{l}
W_{1} \\
W_{2}
\end{array}\right] \times 100
$$

where $W_{1}$ is the weight of the extract after solvent evaporation and $W_{2}$ is the weight of the leaves/seeds taken.

The powdered hydroalcoholic extracts of BPE and MUE were dissolved in distilled water to get desired concentrations before each experiment.

\subsubsection{Phytochemical screening of the plant extracts}

Qualitative phytochemical screening of BPE and MUE was carried out to detect the presence of phytoconstituents, such as tannins, flavonoids, saponins, alkaloids, glycosides, terpenes, and steroids, using standard procedures. Afterward, total phenolic content of the extracts was estimated spectrophotometrically at $723 \mathrm{~nm}$ using UV-Vis spectrophotometer and expressed as Gallic acid equivalent (GAE) milligrams per gram of the extract [17].

To confirm the presence of individual phytocompounds, gas chromatography-mass spectrometry (GC-MS) analysis of plant extracts was carried out. Model QP-2010 Plus (Shimadzu, Japan) of the gas chromatograph mass spectrometer was used for the GC-MS analysis. Samples of BPE and MUE were prepared by mixing them in ethanol and methanol, respectively. The samples were dissolved properly by vortexing. Sample solutions having a concentration of $1 \mathrm{mg} / \mathrm{ml}$ were used for analysis. Out of which 1 $\mu 1$ of sample was injected into an Rtx-5 MS capillary column (30 $\mathrm{m}$ length $\times 0.25 \mathrm{~mm}$ i.d. $\times 0.25 \mu \mathrm{m}$ film thickness) for analysis with injector-detector temperatures to be $250^{\circ} \mathrm{C}$ and $280^{\circ} \mathrm{C}$ respectively. The stepped temperature was programmed as held at $80^{\circ} \mathrm{C}$ for 3 minutes and then from $80^{\circ} \mathrm{C}$ to $280^{\circ} \mathrm{C}$ at a ramp rate of $10^{\circ} \mathrm{C} /$ minute. The retention time of components was compared with standard components provided by different databases such as WILEY8LIB and NIST11LIB for identification [18].

\subsubsection{Determination of antioxidant activity}

The free radical scavenging activity of extracts was evaluated using DPPH and ABTS assays as reported in the literature. DPPH and ABTS assays were carried out according to the method described by Jadid et al. [19] and Saeed et al. [20], respectively.

\subsubsection{Effect of plant extracts on COM crystal-injured cells}

COM crystals were prepared using the method described by Semangoen et al. [21]. Before using, purity of harvested crystals was confirmed by Fourier transform infrared (FTIR) analysis (data not shown) and crystals were exposed to UV radiation to avoid any contamination.

Vero cells were divided into control, injured, and extracttreated groups. Injury was induced by adding fresh DMEM (without serum) containing COM crystals $(200 \mu \mathrm{g} / \mathrm{ml})$. For the extract-treated group, injured cells were exposed to different concentrations of BPE $(10-400 \mu \mathrm{g} / \mathrm{ml})$ and MUE $(10-400 \mu \mathrm{g} /$ $\mathrm{ml}$ ) extracts. Cells exposed to serum-free DMEM without COM crystals were used as control. The effect of BPE and MUE on the repair of cell injury was assessed by measuring cell viability 
through MTT assay [22] against cells injured with COM crystals (injury group without treatment). Percentage cell viability was calculated using the following formula:

$$
\% \text { Cell viability }=\left[\begin{array}{c}
A t-A b \\
A c-A b
\end{array}\right] \times 100
$$

where $A t$ is the absorbance of test sample, $A c$ is the absorbance of control, and $A b$ is the absorbance of blank.

Finally, effective concentrations (EC50 and EC90) of both the extracts, i.e., BPE and MUE, were calculated using AAT bioquest EC50 calculator (https://www.aatbio.com/tools/ec50-calculator/).

\subsubsection{Wound healing assay}

Extracts were evaluated for their wound healing potential through scratch assay using the method reported by Danciu et al. [23]. Cells were divided into test (with extract) and control (without extract) groups. For the test group, cells were exposed to serumfree DMEM containing BPE and MUE extracts at a concentration equivalent to calculated EC50 and EC90 values. Pictures of the scratched surface were taken at different time intervals $(0,3$, 18, and 24 hours) under an inverted microscope (Olympus Life Science) at $10 \times$ magnification. Image Pro-Plus software (Media Cybernetics) was used to compare the images at different time intervals [24] and wound closure percentage was calculated [25] against control.

\section{STATISTICAL ANALYSIS}

Each experiment was carried out in triplicates $(n=3)$ and results were presented as mean $\pm \mathrm{SD}$. GraphPad prism 6.0 software (GraphPad Software, San Diego, CA) was used for data presentation. One-way ANOVA was used to compare differences among different groups. Associated probability $(p)$ value of $<0.05$ was considered as statistically significant.

\section{RESULTS}

\subsection{Preparation of plant extracts}

The $\%$ yield of seeds extract of MUE was $11.4 \%$ as compared to $9.2 \%$ yield of leaves extract of BPE.

\subsection{Phytochemical screening of the plant extracts}

Preliminary phytochemical screening of BPE and MUE confirmed the presence of different classes of bioactive phytoconstituents in the extracts. Tannins, flavonoids, alkaloids, and steroids were found to be present in both the extracts. Unlike MUE, BPE was found to possess saponins. Cardiac glycosides were present in MUE and absent in BPE. Total phenolic contents of BPE and MUE were estimated to be $74.11 \pm 0.003$ and $34.11 \pm 0.0015 \mu \mathrm{g} /$ mg GAE, respectively.

Finally, the extracts were analyzed using GC-MS to screen out specific phytoconstituents. GC-MS analysis of BPE led to the identification of 62 compounds. Out of these, many compounds, such as eucalyptol, 1-tridecanol, terpinyl acetate, beta caryophyllene, squalene, vitamin E, gamma sitosterol, kolavenol acetate, alpha amyrin, etc., are of medical significance (Fig. 1, Table 1).

However, GC-MS analysis of MUE confirmed the presence of medicinally important phytocompounds such as terpinyl acetate, gamma sitosterol, beta caryophyllene, mome inositol, etc. (Fig. 2, Table 2).

\subsection{Determination of antioxidant activity}

BPE exhibited significant radical scavenging activity against DPPH as well as ABTS free radicals. Percentage radical activity increased from $1.91 \%$ to $53.99 \%$ in DPPH assay and $39.26 \%$ $97.44 \%$ in ABTS assay with an increase in the concentration of BPE (12.5-400 $\mu \mathrm{g} / \mathrm{ml})$ (Fig. 3a).

Percentage radical scavenging activity of MUE was comparable with that of BPE. Different concentrations of the extract (12.5$400 \mu \mathrm{g} / \mathrm{ml}$ ) resulted in dose-dependent antioxidant activity from $5.70 \%$ to $45.14 \%$ in DPPH assay and $17.96 \%-96.04 \%$ in ABTS assay (Fig. 3b).

\subsection{Effect of plant extracts on COM crystal-injured cells}

The effect of treatment with BPE and MUE was evaluated using cell viability assay against the injured group (without treatment). Exposure of the cells to COM crystals resulted in more than $40 \%$ decrease in cell viability against control (without COM crystal exposure). However, treatment of the injured cells with different

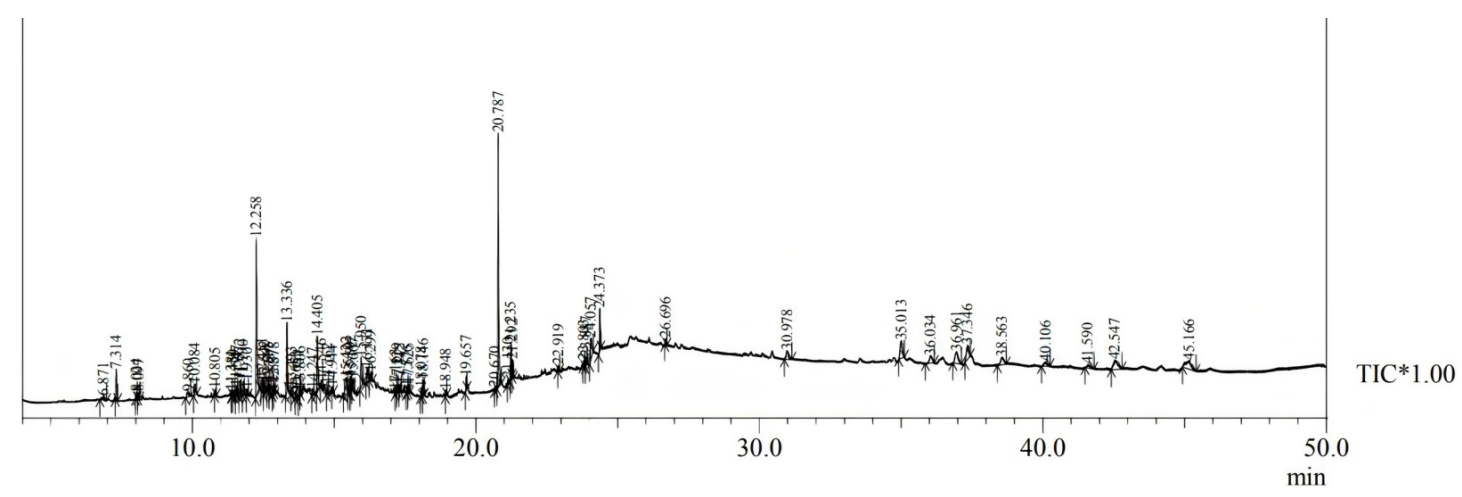

Figure 1: GC-MS chromatogram of hydroalcoholic extract of BPE leaves' extract. 
Table 1: Chemical compositions of hydroalcoholic extract of BPE leaves (GC-MS).

\begin{tabular}{|c|c|c|c|}
\hline S. No. & Name of compound & Retention time & Area\% \\
\hline 1. & 3,3,4-trimethylhexane & 6.871 & 0.61 \\
\hline 2. & Eucalyptol & 7.314 & 1.65 \\
\hline 3. & 2,4-dimethyl-1-heptanol & 8.024 & 0.64 \\
\hline 4. & 1-isopropyl-4-methyl-3-cyclohexen-1-ol & 9.860 & 0.68 \\
\hline 5. & 4-pentenoic acid, 2-methyl-, octyl ester & 10.084 & 1.04 \\
\hline 6. & Linalyl acetate & 10.805 & 0.42 \\
\hline 7. & Isobornyl acetate & 11.381 & 0.24 \\
\hline 8. & Isobornyl thiocyanoacetate & 11.430 & 0.45 \\
\hline 9. & 1-tridecanol & 11.547 & 1.73 \\
\hline 10. & Pentadecafluorooctanoic acid, tetradecyl ester & 11.672 & 1.01 \\
\hline 11. & Myrtenyl acetate & 11.930 & 0.37 \\
\hline 12. & Terpinyl acetate & 12.258 & 11.45 \\
\hline 13. & 14-methyl-8-hexadecyn-1-ol & 12.451 & 0.75 \\
\hline 14. & 4-tert-butylcyclohexyl acetate & 12.542 & 0.90 \\
\hline 15. & 2-heptadecyloxirane & 12.668 & 0.46 \\
\hline 16. & Tricyclo [4-4.0.0 (2,7)] dec-3-ene, 1,3-dimethyl-8-(1-methylethyl) & 12.717 & 0.34 \\
\hline 17. & 1-acetyl-1,4-dihydropyridine & 12.837 & 0.11 \\
\hline 18. & Beta-elemene & 12.878 & 0.41 \\
\hline 19. & Beta-caryophyllene & 13.336 & 4.26 \\
\hline 20. & 2-cyclohexylethyl methylphosphonofluoridate & 13.493 & 0.44 \\
\hline 21. & 3-ethyl-3-methylheptane & 13.653 & 0.28 \\
\hline 22. & 2,8,8-trimethyldecane & 13.757 & 0.31 \\
\hline 23. & 1,4,8-cycloundecatriene, 2,6,6,9-tetramethyl & 13.806 & 0.27 \\
\hline 24. & 10-12-pentacosadiynoic acid & 14.247 & 0.48 \\
\hline 25. & Phenol, 3,5-bis(1,1-dimethylethyl) & 14.405 & 3.98 \\
\hline 26. & 1-octadecanesulphonyl chloride & 14.546 & 0.65 \\
\hline 27. & Nonadecyl pentafluoropropionate & 14.762 & 0.59 \\
\hline 28. & Bicyclo [3.1.1] hept-3-en-2-one, 4,6,6-trimethyl & 14.944 & 0.27 \\
\hline 29. & 2,4,7,14-tetramethyl-4-vinyl-tricyclo $[5 \cdot 4 \cdot 3 \cdot 0(1,8)]$ tetradecan-6-ol & 15.422 & 2.61 \\
\hline 30. & Ethanol, 2-(3,3-dimethylbicyclo [2.2.1] hept-2-ylidene & 15.519 & 0.62 \\
\hline 31. & 2 (3 hours)-furanone, dihydro-5-pentyl & 15.592 & 0.66 \\
\hline 32. & 3-Isopropyl-6,8a-dimethyl-2,3,4,5,8,8a-hexahydro-3a(1 hours)-azulenol & 15.667 & 1.20 \\
\hline 33. & 5-ethyl-1,3-dioxane-5-methanol, tert-butyldimethylsilyl ether & 15.950 & 2.65 \\
\hline 34. & Silane, [(1,1-dimethyl-2-propenyl)oxy]dimethyl & 16.171 & 1.45 \\
\hline 35. & 1-(4-Isopropylphenyl)-2-methylpropyl acetate & 16.299 & 1.11 \\
\hline 36. & $\begin{array}{l}\text { 2-(1-methoxy-2-(trimethylsilyl)ethyl)-4,4-dimethylcyclopentane-1- } \\
\text { carboxaldehyde dimethyl acetal }\end{array}$ & 17.163 & 0.13 \\
\hline 37. & 2,4-diethyl-1-heptanol & 17.229 & 0.38 \\
\hline 38. & Tert-hexadecanethiol & 17.576 & 0.32 \\
\hline 39. & 1-nonadecene & 17.625 & 0.52 \\
\hline 40. & Neophytadiene & 18.078 & 0.48 \\
\hline 41. & 2-pentadecanone, 6,10,14-trimethyl & 18.146 & 1.00 \\
\hline 42. & 7-hexadecenal, (Z) & 18.948 & 0.30 \\
\hline 43. & Hexadecanoic acid, ethyl ester & 19.657 & 0.82 \\
\hline 44. & Diglycolic acid, decyl 2-methylphenyl ester & 20.670 & 0.21 \\
\hline 45. & 3,7,11,15-tetramethylhexadec-2-en-1-ol & 20.787 & 18.11 \\
\hline 46. & Trans, trans-9,12-octadecadienoic acid, propyl ester & 21.235 & 2.04 \\
\hline
\end{tabular}




\begin{tabular}{clrc} 
S. No. & Name of compound & Retention time & Area \% \\
\hline 47. & Ethyl (9Z,12Z)-9,12-octadecadienoate & 21.292 & 0.90 \\
48. & $4,8,12,16$-tetramethylheptadecan-4-olide & 22.919 & 0.34 \\
49. & Benzedrex & 23.803 & 0.42 \\
50. & 1,3,5-trisilacyclohexane & 23.887 & 0.39 \\
51. & 2-ethylbutyric acid, eicosyl ester & 24.057 & 2.46 \\
52. & 1,2-benzenedicarboxylic acid & 24.373 & 2.62 \\
53. & Squalene & 26.696 & 0.40 \\
54. & Vitamin E & 30.978 & 1.60 \\
55. & Gamma-sitosterol & 35.013 & 3.38 \\
56. & 24-noroleana-3,12-diene & 36.034 & 1.46 \\
57. & Kolavenol acetate & 36.961 & 2.88 \\
58. & Alpha-amyrin & 37.346 & 2.81 \\
59. & Olean-12-en-3-one & 38.563 & 2.06 \\
60. & Alpha-caryophyllenol & 41.590 & 0.88 \\
61. & Methyl ursa-2,12-dien-28-oate & 42.547 & 3.28 \\
62. & Benzenepropanoic acid, 3,5-bis(1,1-dimethylethyl)-4-hydroxy-, octadecyl & 45.166 & 3.69
\end{tabular}

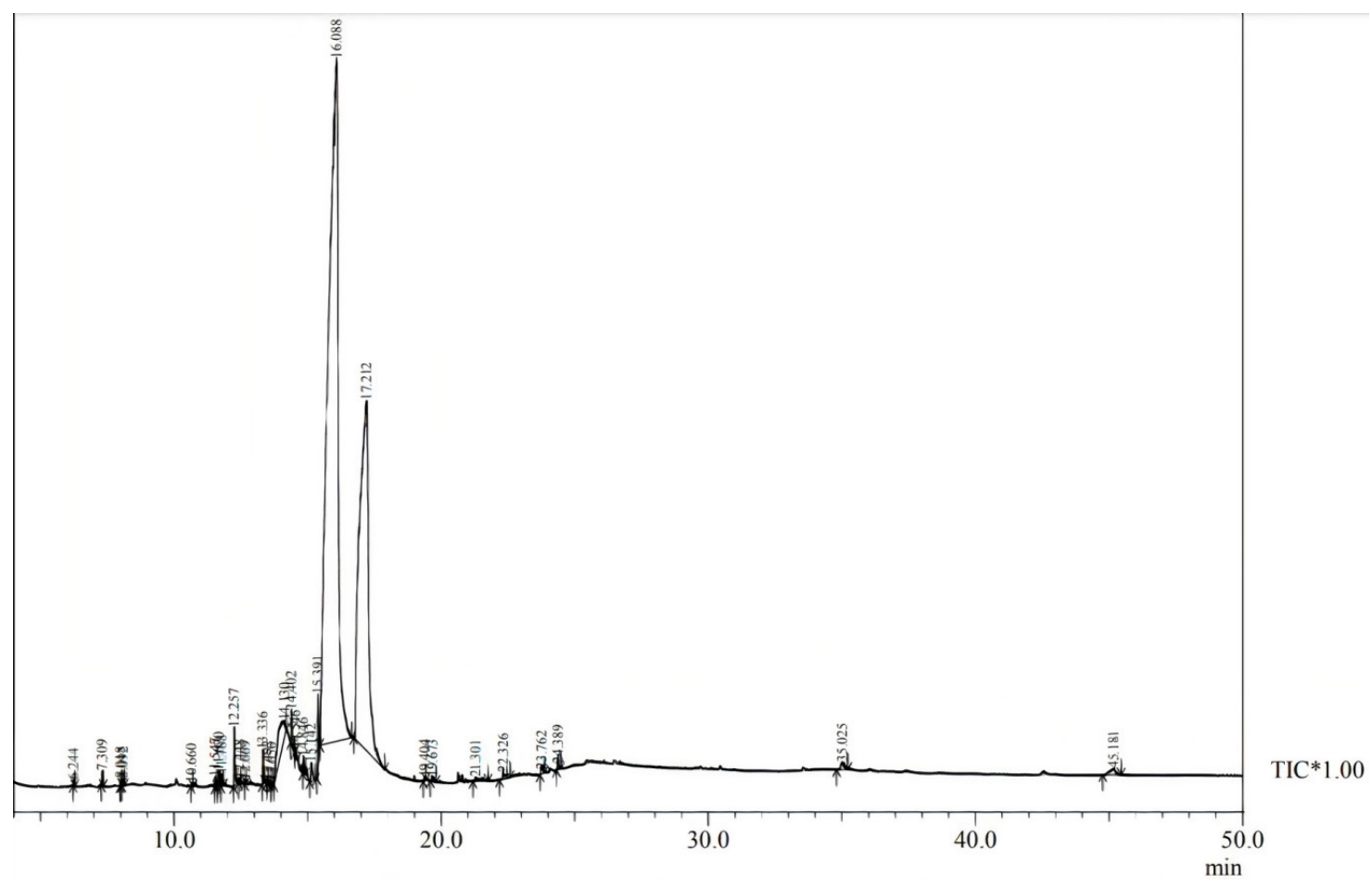

Figure 2: GC-MS chromatogram of hydroalcoholic extract of seeds of MUE.

concentrations of BPE and MUE extracts resulted in significantly improved cell viability which was at a comparable difference with the control group. BPE at a concentration of $200 \mu \mathrm{g} / \mathrm{ml}$ resulted in the retention of $98.5 \%$ viability after COM crystal exposure to Vero cells. The effect was found to be dose-dependent and more than $76.56 \%$ cell viability was retained at the lowest concentration of BPE $(10 \mu \mathrm{g} / \mathrm{ml})$.
Similarly, MUE also exhibited dose-dependent effect on cell viability against the injured group (Fig. 4b). Retained cell viability was found to be in the range of $77.4 \%-90.74 \%$ with different MUE concentrations. Both the extracts showed maximum activity at $200 \mu \mathrm{g} / \mathrm{ml}$.

Using the data of cell viability assay, EC50 and EC90 values were calculated for both the extracts. EC50 and EC90 for BPE were 
Table 2: Chemical compositions of hydroalcoholic extract of seeds of MUE (GC-MS).

\begin{tabular}{|c|c|c|c|}
\hline S. No. & Name of compound & Retention time & Area \% \\
\hline 1. & Tetraethyl silicate & 6.244 & 0.03 \\
\hline 2. & Eucalyptol & 7.309 & 0.09 \\
\hline 3. & Diisodecyl ether & 8.018 & 0.05 \\
\hline 4. & 1-tridecanol & 8.092 & 0.16 \\
\hline 5. & Dodecane, 4,6-dimethyl- & 10.660 & 0.04 \\
\hline 6. & Pentadecafluorooctanoic acid, tetradecyl ester & 11.547 & 0.07 \\
\hline 7. & 2-isopropyl-5-methyl-1-heptanol & 11.788 & 0.08 \\
\hline 8. & Terpinyl acetate & 12.257 & 0.46 \\
\hline 9. & 14-methyl-8-hexadecyn-1-ol & 12.448 & 0.04 \\
\hline 10. & Cyclohexanol, 5-methyl-2-(1-methylethyl)-, acetate & 12.669 & 0.02 \\
\hline 11. & Beta-caryophyllene & 13.336 & 0.21 \\
\hline 12. & Cholestan-22(26)-isoepoxy & 13.492 & 0.03 \\
\hline 13. & 1,8-nonadien-3-ol & 14.130 & 2.06 \\
\hline 14. & 3,5-bis(1,1-dimethylethyl)phenol & 14.402 & 0.29 \\
\hline 15. & Oxirane, [(dodecyloxy)methyl $]$ & 14.546 & 0.05 \\
\hline 16. & Cyclopropanemethanol, alpha,2-dimethyl-2-(4-methyl-3-pentenyl & 14.846 & 0.18 \\
\hline 17. & 5,9-undecadien-2-ol, 6,10-dimethyl & 15.142 & 0.28 \\
\hline 18. & 5-ethyl-1,3-dioxane-5-methanol, tert-butyldimethylsilyl ether & 15.391 & 0.78 \\
\hline 19. & Methyl. alpha.-D-galactoside & 16.088 & 64.28 \\
\hline 20. & Mome inositol & 17.212 & 29.52 \\
\hline 21. & 2-aminoethanethiol hydrogen sulfate (ester) & 19.404 & 0.04 \\
\hline 22. & Heptadecanoic acid, ethyl ester & 19.673 & 0.07 \\
\hline 23. & $(\mathrm{Z}, \mathrm{z})$-6,9-cis-3,4-epoxy-nonadecadiene & 21.301 & 0.20 \\
\hline 24. & 3-cyclopentylpropionic acid, 2-dimethylaminoethyl ester & 22.326 & 0.19 \\
\hline 25. & Hexanoic acid, 2-dimethylaminoethyl ester & 23.762 & 0.13 \\
\hline 26. & 1,2-benzenedicarboxylic acid, diisooctyle & 24.389 & 0.12 \\
\hline 27. & Gamma.-sitosterol & 35.025 & 0.20 \\
\hline 28. & Benzenepropanoic acid, 3,5-bis(1,1-dimethylethyl)-4- hydroxy-, octadecyl ester & 45.181 & 0.34 \\
\hline
\end{tabular}

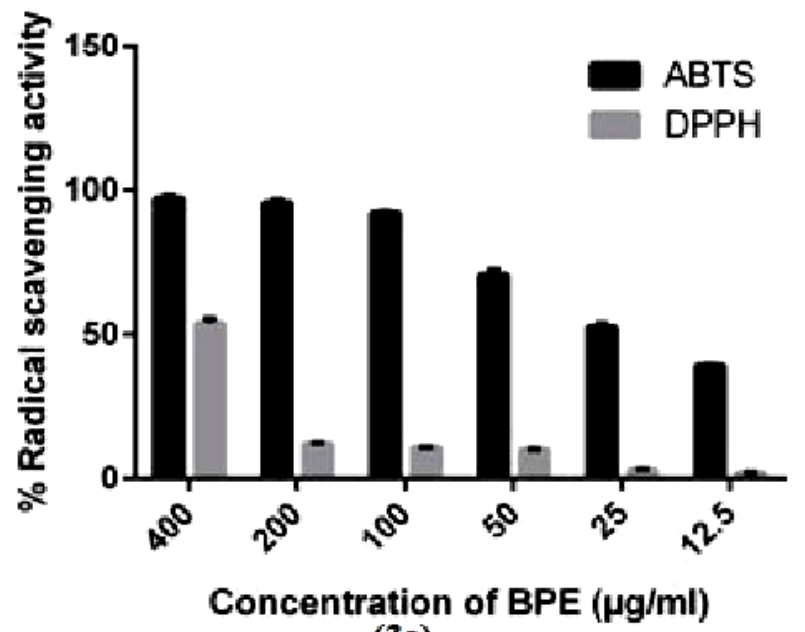

(3a)

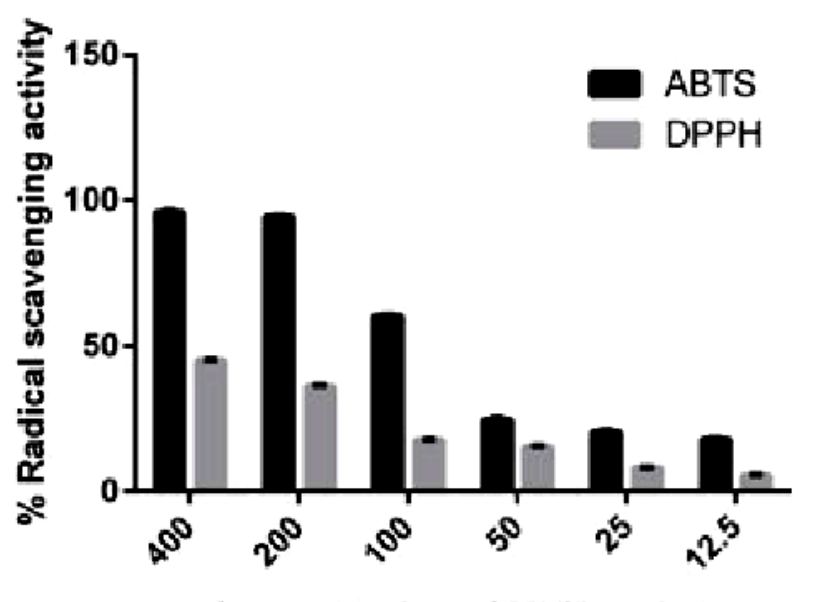

Concentration of MUE ( $\mu \mathrm{g} / \mathrm{ml})$

(3b)

Figure 3: Free radical scavenging potential of BPE (3a) and MUE (3b). Results are expressed as mean \pm SD. 


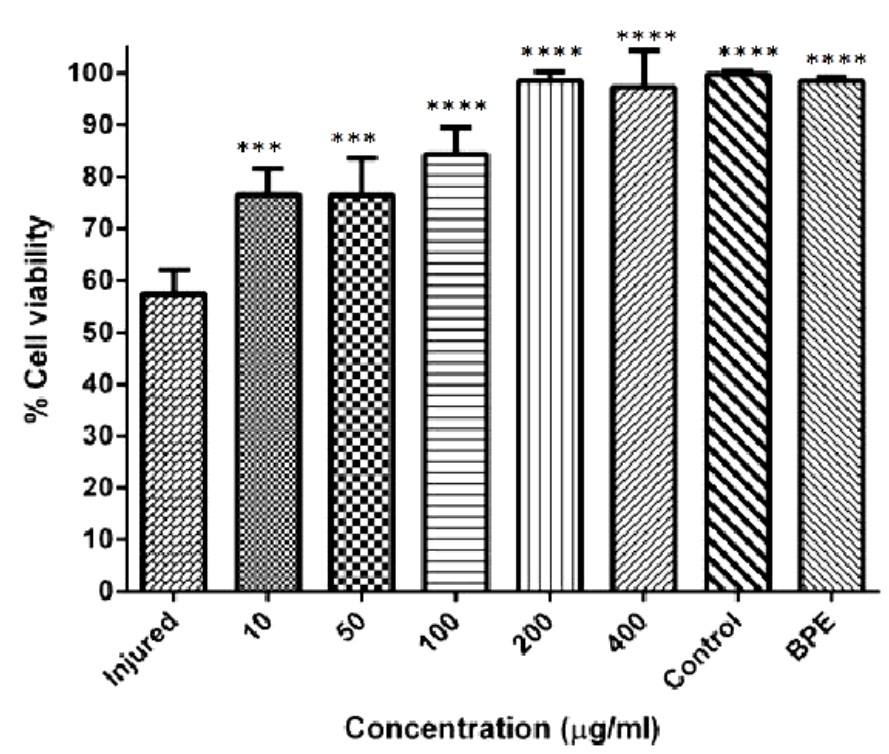

(4a)

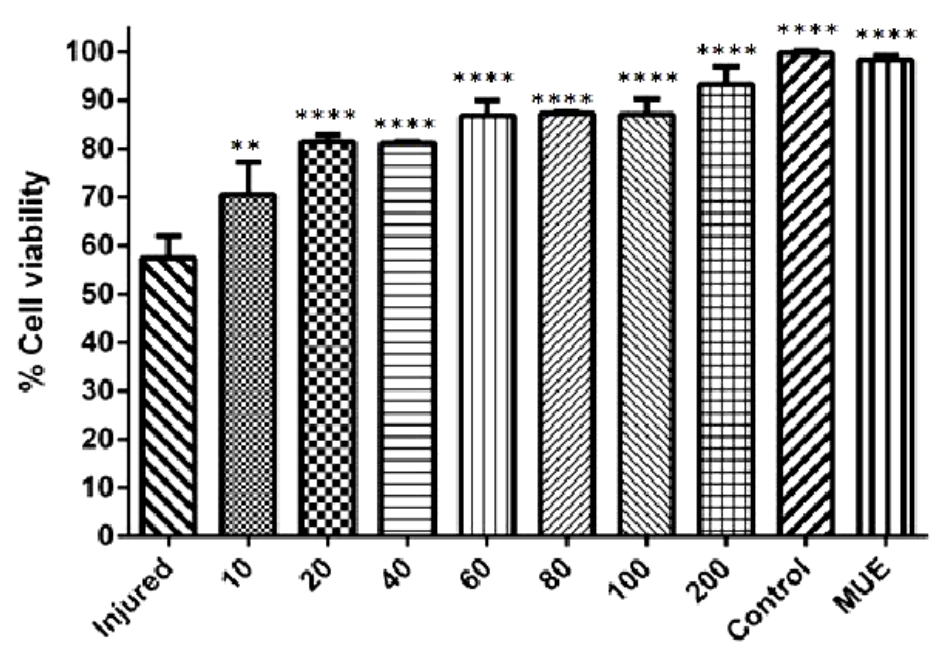

Concentration $(\mu \mathrm{g} / \mathrm{ml})$

(4b)

Figure 4: Treatment of COM crystal injured Vero cells with BPE (4a) and MUE (4b). Activity of both plant extracts was dose-dependent. Values are expressed as mean $\pm \mathrm{SD}$.

${ }^{* *} p<0.005,{ }^{* * *} p<0.0005$, and $* * * * p<0.0001$ versus injured group of cells.

found to be 104.26 and $109.18 \mu \mathrm{g} / \mathrm{ml}$, respectively. However, in case of MUE, EC50 and EC90 were found to be 74.64 and 246.09 $\mu \mathrm{g} / \mathrm{ml}$, respectively.

\subsection{Wound healing assay}

Wound healing potential of both the extracts was evaluated at EC50 and EC90 concentrations. Treatment with EC50 of BPE (Fig. 5a) resulted in $84.48 \%$ wound closure after 24 hours which was significantly higher than the control group (73.79\%). However, treatment with EC90 of BPE led to $74.08 \%$ wound closure which was not at a significant difference with the control (Fig. 5b). EC50 and EC90 of MUE resulted in $85.66 \%$ and $91.09 \%$ wound closure which were significantly higher than the control group (Fig. 5c), respectively.

\section{DISCUSSION}

Urolithiasis remains a medical challenge worldwide and the problem is increasing day by day due to the modern lifestyle. Moreover, the recurrence rate of urolithiasis is very high. In the present study, we evaluated the antioxidant, wound healing assays, and anti-urolithiatic potential of hydroalcoholic extracts of BPE and MUE. Both extracts exhibited dose-dependent radical scavenging activity against DPPH as well as ABTS free radicals. In the cell viability assay, it was observed that exposure of the Vero cells to COM crystals significantly reduced the cell viability to $57.4 \%$ with respect to $100 \%$ in case of control group (without COM crystal treatment). The data clearly indicated that exposure of the cells to COM crystals resulted in cytotoxicity and the results were found to be in agreement with the findings of Mittal et al. [26]. Interestingly, the treatment of injured cells with the plant extracts resulted in a dose-dependent significant improvement $(p<$
$0.0005)$ in the retained cell viability even at a lower concentration $(10 \mu \mathrm{g} / \mathrm{ml})$ for the BPE and MUE versus injured group. When we increased the extract concentration from 10 to $400 \mu \mathrm{g} / \mathrm{ml}$, there was a significant increase in the retained cell viability. The results were found comparable to the control group at higher concentration of BPE (above $200 \mu \mathrm{g} / \mathrm{ml}$ ). The exact mechanism responsible for this improved cytoprotective activity is not clear yet but it may be correlated with high antioxidant property and excellent wound healing potential of both the extracts.

MUE exhibited better wound healing efficacy than BPE when compared to control (untreated group). Treatment with EC50 of BPE resulted in significant improvement $(p<0.05)$ in wound closure. However, both EC50 $(p<0.0005)$ and EC90 $(p<$ 0.0001 ) of MUE led to improved wound closure rates and were at comparable differences with the control. The results of the cell viability assay, antioxidant activity, and wound healing assay may be correlated with a number of pharmacologically active phytoconstituent identified during preliminary screening and GCMS. Phytocompounds such as eucalyptol, 1-tridecanol, terpinyl acetate, beta caryophyllene, 3, 7, 11, 15-tetramethylhexadec2-en-1-ol, squalene, vitamin E, gamma sitosterol, kolavenol acetate, and alpha amyrin are capable of influencing metabolic reactions in different ways. Eucalyptol is reported to possess ulcer healing abilities involving antioxidant and cytoprotective effect [27]. A sesquiterpene, $\beta$-caryophyllene which was present in a significant concentration in BPE, has also been investigated for its cytoprotective effects and antioxidant activities [28,29]. Vitamin E along with another compound 3, 7, 11, 15-tetramethylhexadec2-en-1-ol, which is also known as phytol, was found in significant concentrations in BPE. Phytol is a precursor of vitamin $\mathrm{E}$ and can be considered as a source of antioxidant [30,31]. Another polyunsaturated hydrocarbon squalene present in BPE is capable 

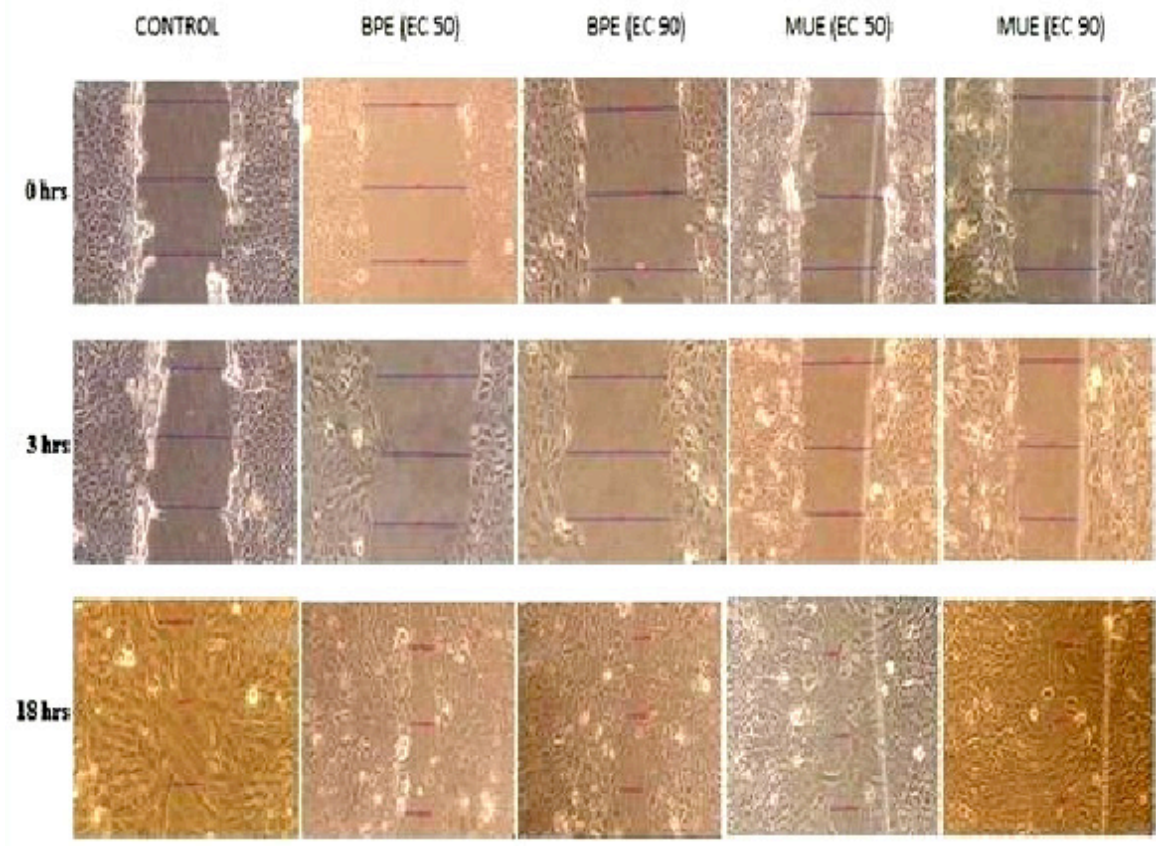

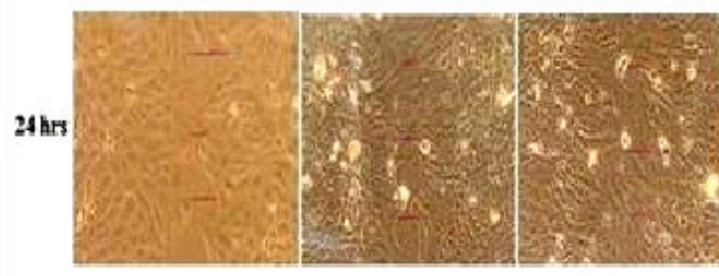

(5a)

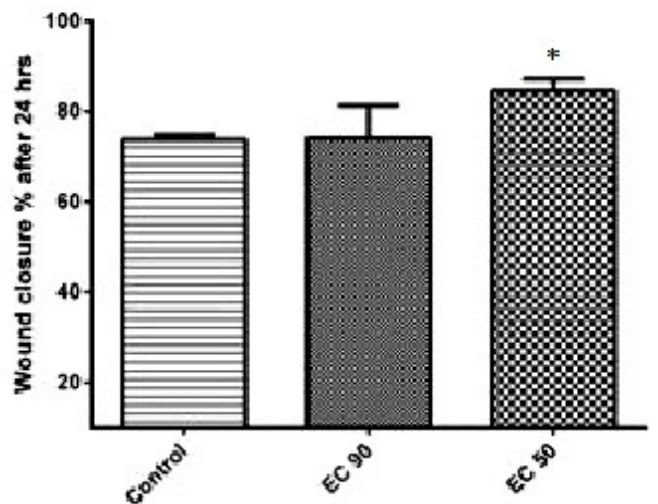

(5b)

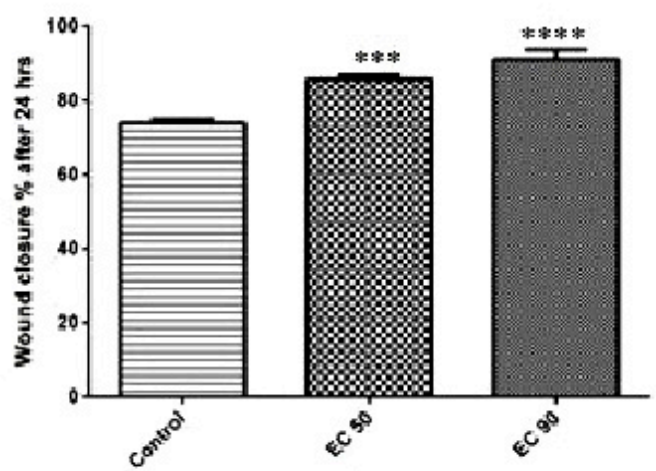

(5c)

Figure 5: Image showing wound closure at different time points (5a). Percentage of wound closure in BPE (5b) and MUE (5c) treated groups. Values are expressed as mean $\pm \mathrm{SD}$

${ }^{*} p<0.05,{ }^{* * *} p<0.0005$, and ${ }^{* * * *} p<0.0001$ versus untreated control .

of preventing oxidative damage and act as a natural antioxidant $[32,33]$. Beta elemene and its derivatives, present in BPE, are already reported to possess potent antioxidant activity against ROS production [34]. The presence of mome inositol as a major phytoconsituent along with terpinyl acetate, gamma sitosterol, and beta caryophyllene in smaller amounts in MUE also justifies its role in repairing the cell damage due to COM crystal exposure. The literature reveals the antioxidant activity of alpha amyrin [35]. These phytocompounds could be responsible for providing the extract its antioxidant and wound healing abilities. Many medicinal properties have already been attributed to mome inositol, such as antialopecic, anticirrhotic, antineuropathic, cholesterolytic, lipotropic, and sweetener [36,37].

The presence of eucalyptol, $\beta$-caryophyllene, vitamin E, phytol, and squalene may be providing the antioxidative property to BPE. In MUE also, the presence of compounds like mome inositol, terpinyl acetate, $\beta$-caryophyllene, etc. could probably be the factors attributing its antioxidative potential.

In recent years, many surgical and nonsurgical treatment methods for urolithiasis have been emerged, but recurrence of the disease remains a challenge with modern treatment modalities. According to the literature, the generation of free radicals in kidneys plays the key role in the pathogenesis of renal calculi [38]. In such conditions, using plant-derived antioxidants can be a wonderful approach to combat urolithiasis. Seeds of MUE and leaves of BPE are rich sources of antioxidants and have been used traditionally to treat kidney stones, thus serving the purpose.

\section{CONCLUSION}

In summary, hydroalcoholic extracts of MUE and BPE are rich in phytocompounds having antioxidative, cytoprotective, and wound healing properties. They are capable of protecting the renal cells which are injured with calcium oxalate crystals. However, specific phytochemicals of the extracts may be explored for therapeutic efficacy against urolithiasis.

\section{ACKNOWLEDGMENT}

The authors would like to acknowledge Jaypee Institute of Information Technology, Noida, India, for providing the facilities to conduct the research work. 


\section{AUTHORS' CONTRIBUTIONS}

We, the authors hereby declare that both authors have made substantial contributions to the conception and design, acquisition of data, or analysis and interpretation of data; took part in drafting the article or revising it critically for important intellectual content and both agreed to submit to the current journal. Therefore, both the authors are eligible to be an author as per the International Committee of Medical Journal Editors (ICMJE) requirements/ guidelines.

\section{FUNDING}

There is no funding to report.

\section{CONFLICT OF INTEREST}

The authors declare that they have no financial or any other conflicts of interest in this work.

\section{ETHICAL APPROVAL}

Not applicable.

\section{ABBREVIATIONS}

ABTS: 2,2'-azinobis (3-ethylbenzothiazoline-6-sulfonic acid) diammonium salt

BPE: Bryophyllum pinnatum leaves' extract

COM: Calcium oxalate monohydrate

DMSO: Dimethyl sulfoxide

DPPH: 2,2-Diphenyl-1-picrylhydrazyl

GC-MS: Gas chromatography-mass spectrometry

MUE: Macrotyloma uniflorum seeds' extract.

\section{REFERENCES}

1. Daudon M, Jungers P, Bazin D, Williams JC. Recurrence rates of urinary calculi according to stone composition and morphology. Urolithiasis 2018;46(5):459-70.

2. Shafi H, Moazzami B, Pourghasem M, Kasaeian A. An overview of treatment options for urinary stones. Casp J Intern Med 2016;7(1):1-6.

3. Gomase PV, Pawar SP. Urolithiasis (kidney stones) current pharmacological diagnosis and management. J Drug Deliv Ther 2019;9(4):726-37.

4. Patle A, Hatware KV, Patil K, Sharma S, Gupta G. Role of herbal medicine in the management of urolithiasis - a review for future perspectives. J Environ Pathol Toxicol Oncol 2019;38(2):97-118.

5. Chaiyarit S, Thongboonkerd V. Changes in mitochondrial proteome of renal tubular cells induced by calcium oxalate monohydrate crystal adhesion and internalization are related to mitochondrial dysfunction. J Proteome Res 2012;11(6):3269-80.

6. Yu L, Gan X, Liu X, An R. Calcium oxalate crystals induces tight junction disruption in distal renal tubular epithelial cells by activating ROS/Akt/p38 MAPK signaling pathway. Ren Fail 2017;39(1):44051.

7. Khan SR. Histological aspects of the "fixed-particle" model of stone formation: animal studies. Urolithiasis 2017;45(1):75-87.

8. Khamchun S, Thongboonkerd V. Cell cycle shift from G0/G1 to S and $\mathrm{G} 2 / \mathrm{M}$ phases is responsible for increased adhesion of calcium oxalate crystals on repairing renal tubular cells at injured site. Cell Death Discov 2018;4(1):1-2.

9. Gan QZ, Sun XY, Bhadja P, Yao XQ, Ouyang JM. Reinjury risk of nano-calcium oxalate monohydrate and calcium oxalate dihydrate crystals on injured renal epithelial cells: aggravation of crystal adhesion and aggregation. Int J Nanomed 2016;11:2839-54.

10. Nirumand MC, Hajialyani M, Rahimi R, Farzaei MH, Zingue S, Nabavi SM, et al. Dietary plants for the prevention and management of kidney stones: preclinical and clinical evidence and molecular mechanisms. Int J Mol Sci 2018;19(3):765.

11. Ozoluaa RI, Eboka CJ, Durua CN, Uwayaa DO. Effects of aqueous leaf extract of Bryophyllum pinnatum on guinea pig tracheal ring contractility. Niger J Physiol Sci 2010;25(2):149-57.

12. Adibe MK, Gabriel IM, Akintunde AAM, Esther AO. Chemical compositions and antioxidant activity of leaf and stem essential oils of Bryophyllum pinnatum (lam.) Kurz. GSC Biol Pharm Sci 2019;9(2):057-64.

13. Upadhyay S, Jain V, Upadhyay U. Glossary of Dolichos biflorous-A Legume with miraculous activities. Res J Pharmacol Pharmacodyn 2015;7(2):103-16.

14. Ahmed S, Hasan MM, Mahmood ZA. Antiurolithiatic plants: multidimensional pharmacology. J Pharmacogn Phytochem 2016;5(2):4.

15. Shukla AK, Shukla S, Garg A, Garg S. A review on anti-urolithiatic activity of herbal folk plants. Asian J Biomater Res 2017;3(2):1-1.

16. Ahmed S, Hasan MM, Mahmood ZA. Antiurolithiatic plants in different countries and cultures. J Pharmacogn Phytochem 2016;5(1):102.

17. Bonomo MG, Cafaro C, Russo D, Calabrone L, Milella L, Saturnino C, et al. Antimicrobial activity, antioxidant properties and phytochemical screening of Aesculus hippocastanum mother tincture against foodborne bacteria. Lett Drug Des Discov 2020;17(1):48-56.

18. Painuli S, Rai N, Kumar N. Gas chromatography and mass spectrometry analysis of a methanolic extract of leaves of Rhododendron arboreum. GAS 2016;9(1):101-4.

19. Jadid N, Hidayati D, Hartanti SR, Arraniry BA, Rachman RY, Wikanta W. Antioxidant activities of different solvent extracts of Piper retrofractum Vahl. using DPPH assay. Paper presented at: AIP Conference Proceedings, 2017.

20. Saeed N, Khan MR, Shabbir M. Antioxidant activity, total phenolic and total flavonoid contents of whole plant extracts Torilis leptophylla L. BMC Complement Altern Med 2012;12(1):221.

21. Semangoen T, Sinchaikul S, Chen ST, Thongboonkerd V. Proteomic analysis of altered proteins in distal renal tubular cells in response to calcium oxalate monohydrate crystal adhesion: Implications for kidney stone disease. Proteomics Clin Appl 2008;2(7-8):1099-109.

22. Kumar P, Nagarajan A, Uchil PD. Analysis of cell viability by the MTT assay. Cold Spring Harb Protoc 2018;2018(6):469-471.

23. Danciu C, Muntean D, Alexa E, Farcas C, Oprean C, Zupko I, et al. Phytochemical characterization and evaluation of the antimicrobial, antiproliferative and pro-apoptotic potential of Ephedra alata Decne. hydroalcoholic extract against the MCF-7 breast cancer cell line. Molecules 2019;24(1):13.

24. Liang CC, Park AY, Guan JL. In vitro scratch assay: a convenient and inexpensive method for analysis of cell migration in vitro. Nature Protoc 2007;2(2):329-33.

25. Felice F, Zambito Y, Belardinelli E, Fabiano A, Santoni T, Di Stefano R. Effect of different chitosan derivatives on in vitro scratch wound assay: a comparative study. Int J Biol Macromol 2015;76:236-41.

26. Mittal A, Tandon S, Singla S, Tandon C. In vitro inhibition of calcium oxalate crystallization and crystal adherence to renal tubular epithelial cells by Terminalia arjuna. Urolithiasis 2016;44(2):117-25.

27. Caldas GFR, da Silva Oliveira AR, Araújo AV, Lafayette SS, Albuquerque GS, Silva-Neto Jda C, et al. Gastroprotective mechanisms of the monoterpene 1, 8-cineole (eucalyptol). PLoS One 2015;10(8):e0134558. 
28. Francomano F, Caruso A, Barbarossa A, Fazio A, La Torre C, Ceramella J, et al. $\beta$-Caryophyllene: a sesquiterpene with countless biological properties. Appl Sci 2019;9(24):5420.

29. Al-Taee H, Azimullah S, Meeran MN, Alaraj Almheiri MK, Al Jasmi RA, et al. $\beta$-caryophyllene, a dietary phytocannabinoid attenuates oxidative stress, inflammation, apoptosis and prevents structural alterations of the myocardium against doxorubicin-induced acute cardiotoxicity in rats: an in vitro and in vivo study. Eur J Pharmacol 2019;858:172467.

30. Byju K, Vasundhara G, Anuradha V, Nair S, Kumar N. Presence of phytol, a precursor of vitamin $\mathrm{E}$ in Chaetomorpha antinnina. Mapana J Sci 2013;12(2):57-65.

31. Islam MT, Ali ES, Uddin SJ, Shaw S, Islam MA, Ahmed MI, et al. Phytol: a review of biomedical activities. Food Chem Toxicol 2018;121:82-94.

32. Kabuto H, Yamanushi TT, Janjua N, Takayama F, Mankura M. Effects of squalene/squalane on dopamine levels, antioxidant enzyme activity, and fatty acid composition in the striatum of Parkinson's disease mouse model. J Oleo Sci 2013;62(1):21-8.

33. Micera M, Botto A, Geddo F, Antoniotti S, Bertea CM, Levi R, et al. Squalene: more than a step toward sterols. Antioxidants 2020;9(8):688.

34. Chen J, Duan W, Bai R, Yao H, Shang J, Xu J. Design, synthesis and antioxidant activity evaluation of novel $\beta$-elemene derivatives. Bioorga Med Chem Lett 2014;24(15):3407-11.

35. Santos FA, Frota JT, Arruda BR, de Melo TS, da Silva AA, Brito GA, et al. Antihyperglycemic and hypolipidemic effects of $\alpha, \beta$-amyrin, a triterpenoid mixture from Protium heptaphyllum in mice. Lipids Health Dis 2012;11(1):1-8.
36. Das S, Vasudeva N, Sharma S. Chemical composition of ethanol extract of Macrotyloma uniflorum (Lam.) Verdc. using GC-MS spectroscopy. Org Med Chem Lett 2014;4(1):13.

37. Kumar NR, Reddy JS, Gopikrishna G, Solomon KA. GC-MS determination of bioactive constituents of Cycas beddomei cones. Int J Pharm Bio Sci 2012;3(3):344-50.

38. Ceban E, Banov P, Galescu A, Botnari V. Oxidative stress and antioxidant status in patients with complicated urolithiasis. J Med Life 2016;9(3):259.

\section{How to cite this article:}

Priyadarshini, Faujdar C. Comparative study of hydroalcoholic extracts of Bryophyllum pinnatum and Macrotyloma uniflorum for their antioxidant, antiurolithiatic, and wound healing potential. J Appl Biol Biotech 2022; 10(01):196-205. 